\section{Intraductal Pneumatic Lithotripsy after Extended Transoral Duct Surgery in Submandibular Sialolithiasis}

\author{
Michael Koch, MD', Mirco Schapher, MD', \\ Konstantinos Mantsopoulos, MD, PhD', \\ Miguel Goncalves, MD', and Heinrich Iro, MD'
}

Otolaryngology-

Head and Neck Surgery

2019, Vol. 160(I) 63-69

(C) American Academy of

Otolaryngology-Head and Neck

Surgery Foundation 2018

Reprints and permission:

sagepub.com/journalsPermissions.nav DOI: $10.1177 / 0194599818802224$ http://otojournal.org

@SAGE
No sponsorships or competing interests have been disclosed for this article.

\begin{abstract}
Objective. Persistent, residual, or recurrent stones after transoral duct surgery are always associated with hilar to intraparenchymal and/or multiple sialolithiasis, causing difficulties in the treatment. This study was performed to assess the value of intraductal lithotripsy in the treatment of persistent, residual, or recurrent sialolithiasis after extended duct surgery in the submandibular gland.
\end{abstract}

Study Design. Retrospective study covering February 2015 to June 2018.

Study Setting. Tertiary referral center for salivary gland diseases.

Subjects and Methods. After extended ductal surgery, 39 patients presenting with persistent, residual, or recurrent stones were treated. Four patients had persistent stones; 16 had residual stones; and 19 presented with recurrent stones. Among these patients, 50 stones were treated with intraductal pneumatic lithotripsy. Fragmentation rate, stonefree rate, and symptom-free rate after treatment with intraductal lithotripsy were outcome measures.

Results. Of the 39 patients, $97.4 \%$ became stone-free, and all were symptom-free. Ninety-eight percent of the stones were completely fragmented. For $23.1 \%$ of the patients, >I stone was treated with intraductal lithotripsy. All patients with persistent stones, $93.7 \%$ of those with residual stones, and all with recurrent stones became stone-free and symptom-free. No severe complications developed.

Conclusions. This study shows that patients presenting with difficult and/or multiple sialolithiasis after extended transoral submandibular duct surgery can be treated with success rates $>97 \%$. For multiple sialolithiasis in particular, a multimodal treatment approach with interventional sialendoscopy and intraductal lithotripsy as a central element is a prerequisite for success, as this enables the most difficult part to be performed with high success rates.

\section{Keywords}

salivary, stones, submandibular, sialolithiasis, sialendoscopy, intraductal lithotripsy

Received May 30, 20I8; revised July 25, 20I8; accepted August 3I, 2018.

$\mathrm{O}_{10 \mathrm{i}}$ ialolithiasis is the cause of obstructive sialadenopathy in $60 \%$ to $70 \%$ of cases, and $80 \%$ of all stones are located in the submandibular gland. Of these, $>50 \%$ are located hilar or posthilar, while $10 \%$ are intraparenchymal. ${ }^{1,2}$ A multimodal treatment regimen was developed to treat these stones, with interventional sialendoscopy (ISE), transoral duct surgery (TDS), and extracorporeal shock wave lithotripsy (ESWL) being the most important modalities used. ${ }^{3-8}$ Extended TDS (eTDS) in particular, which can extend to opening of the hilum and gland tissue (submandibulotomy), is the most effective method for stones in proximal to posthilar locations, ${ }^{3,7,9-19}$ with good long-term results reported. ${ }^{16,18,19}$ Sialendoscopy-assisted surgery is a modification to further reduce the invasiveness of $\mathrm{TDS}^{20-26}$ Recovery of glandular function and anatomic structures was observed after the removal of hilar stones. ${ }^{26}$

Limitations for TDS were reported to be deep hilar, posthilar, or intraparenchymal locations of (impacted) stones, in combination with specific anatomic characteristics of the submandibular ductal system. ${ }^{19,27-29}$ Hilar ultrasound-guided ductal surgery, ${ }^{12,19}$ supplementation with sialendoscopyguided fragmentation with a drill and basket or forceps extraction, ${ }^{7}$ and concomitant ESWL $^{30}$ were described as options in such cases. Despite these methods, it is not possible to remove all single stones in the deep hilar or posthilar

\footnotetext{
'Department of Otorhinolaryngology-Head and Neck Surgery, University of Erlangen-Nuremberg, Erlangen, Germany

Corresponding Author:

Michael Koch, MD, Department of Otorhinolaryngology-Head and Neck Surgery, Friedrich-Alexander University of Erlangen-Nuremberg,

Waldstrasse I, D-91054 Erlangen, Germany.

Email: michael.koch@uk-erlangen.de
} 
Table I. Patients, Stones, and Failure Rates after Treatment of Persistent, Residual, and Recurrent Stones with Pneumatic IPL after eTDS.

\begin{tabular}{|c|c|c|c|c|c|c|}
\hline $\begin{array}{l}\text { SMGs (Patients, n; } \\
\text { Stones, n) }\end{array}$ & \multicolumn{3}{|c|}{ Patients, $\mathrm{n}$; Total Stones, $\mathrm{n}$} & \multicolumn{3}{|c|}{ After Treatment with IPL $(\mathrm{n}, \%)$} \\
\hline All stones $(39 ; 50)$ & $30 ; 30$ & $7 ; 14$ & $2 ; 6$ & I of $39(2.6)$ & 2 of $39(5.1)$ & 2 of $39(5.1)$ \\
\hline Persistent stones $(4 ; 4)$ & $4 ; 4$ & - & - & 0 & - & - \\
\hline Residual stones (16; 24) & $9 ; 9$ & $6 ; 12$ & $\mathrm{I} ; 3$ & I of $16(6.25)$ & I of $16(6.25)$ & I of $16(6.25)$ \\
\hline
\end{tabular}

Abbreviations: eTDS, extended transoral duct surgery; IPL, intraductal pneumatic lithotripsy; SMG, submandibular gland.

region with TDS, with or without ISE. ${ }^{19,31}$ In addition, patients present with multiple stones in $15 \%$ to $20 \%$ of cases and with recurrent stones in $5 \%$ to $15 \%$ of cases, also after TDS. ${ }^{1,2,25,32,33}$

For patients with persistent stones (unsuccessful removal), residual stones (partial stone extraction in multiple sialolithiasis), and/or recurrent stones (after complete stone removal), surgical revision of the hilar neo-ostium or dilatational manipulation is often difficult due to a posthilar ductal system that is characterized by a relatively narrow ductal lumen and too long a distance to the stone bed. Revision TDS (eg, with insertion of a clamp and other larger surgical instruments) does not appear to be the best solution, since damage to hilar structures may be associated with scar formation in the neo-ostium and the posthilar duct system. If ESWL is performed, sufficient fragmentation may not be achieved. ${ }^{30,34,35}$

Intraductal pneumatic lithotripsy (IPL) provides new options in these difficult situations. Laser lithotripsy with a holmium-YAG laser $^{36}$ and pneumatic lithotripsy ${ }^{37,38}$ were successfully used to treat posthilar or nearly intraparenchymal stones, with success rates $>90 \%$. In addition to recurrent stones, it may be possible to treat persistent and residual stones successfully with IPL after TDS after a healing period with the development of a stable neo-ostium. The aim of the present study was to examine the value of IPL in persistent, residual, and recurrent stones after prior eTDS. ${ }^{37}$

\section{Methods}

This retrospective study was carried out at the Department of Otorhinolaryngology-Head and Neck Surgery at the University of Erlangen-Nuremberg, Germany. The study time was February 2015 to June 2018. Approval for the study was obtained from the local institutional review board at Friedrich Alexander University of Erlangen-Nuremberg.

For diagnosis, all patients underwent an ultrasound examination, which was carried out with high-end ultrasound devices (Siemens ACUSON S2000/S3000; Siemens Medical Solutions USA Inc, Malvern, Pennsylvania). The patients had undergone eTDS 2 months to 11 years previously, and if it was performed in our department (37 of 39, 94.9\%), it was carried out in accordance with established algorithms. ${ }^{6}$

IPL was performed as a salvage procedure in persistent and recurrent stones and as a secondary procedure in residual stones. After IPL, residual fragments and fibrinous plaques were regularly removed at the check-up sialendoscopies on the first and second days. Further follow-up sialendoscopies were planned 4 to 8 weeks and 1 year after IPL.

Statistical analysis was performed with SPSS Statistics for Windows (version 22.0; IBM Corporation, Armonk, New York). Data are given as mean \pm SEM. Differences among independent groups (persistent, residual, and recurrent stones) were calculated with the nonparametric Kruskal-Wallis test. Bivariate correlations between parameters were calculated with the Spearman correlation coefficient. $P$ values $<.05$ were considered significant.

\section{Results}

Fifty stones in 39 patients were treated with pneumatic IPL due to persistent, residual, or recurrent stones after prior eTDS. The mean age was $50.3 \pm 2.1$ years (range, 24-81); $76.9 \%$ were men ( 30 of 39 ); and $23.1 \%$ were women ( 9 of 39). Symptoms were reported to occur daily or at last several times per week with variable intensity, with no obvious differences observable among patients with persistent, residual, or recurrent stones. All procedures were performed with local anesthesia (tetracaine $1 \%-2 \%, 5-10 \mathrm{~mL}$ ) and were well tolerated by the patients. The size of the stones treated with IPL was $6.68 \pm 0.46 \mathrm{~mm}$. Several stones were treated in 9 patients (Table I). Between 1 and 4 lithotripsies per patient were performed. Two IPL procedures were performed in 7 patients ( 5 with 1 stone, 2 with 2 stones); 3 lithotripsies in 4 patients ( 1 with 1 stone, 2 with 2 stones, 1 with 3 stones); and 4 IPL procedures in 1 patient (with 1 stone; Table 2). A mean $120.28 \pm 21.97$ strikes per stone and $1.18 \pm 0.1$ IPL procedures per stone were performed. The mean duration of the procedure per stone was $67 \pm$ 8.6 minutes. There were significant correlations between stone size and the number of strikes per stone $(0.513, P=$ $.0001)$, the number of IPL procedures per stone $(0.502$, $P=.0001)$, and the duration of IPL per stone $(0.656$, $P=.0001)$.

Forty-nine stones $(98 \%)$ were completely fragmented. One stone had subtotal/nearly complete fragmentation after 1 IPL. Of the 39 patients, 38 (97.4\%) became stone-free, and all were symptom-free (Table 2). All glands were preserved after this treatment cycle.

Multiple stones were present in $46.2 \%$ of all patients ( 18 of 39 ) and $51.4 \%$ of patients with residual or recurrent 
Table 2. Results of Treatment of Persistent, Residual, and Recurrent Stones after eTDS with IPL.

\begin{tabular}{|c|c|c|c|c|c|}
\hline \multirow[b]{2}{*}{$\begin{array}{l}\text { SMGs (Patients, n; } \\
\text { Stones, n) }\end{array}$} & \multicolumn{4}{|c|}{ Mean \pm SEM (Median; Range) } & \multirow[b]{2}{*}{$\begin{array}{l}\text { Stones with Complete } \\
\text { Fragmentation, n (\%) }\end{array}$} \\
\hline & $\begin{array}{c}\text { Size of } \\
\text { Stone, } \mathrm{mm}\end{array}$ & $\begin{array}{l}\text { Lithotripsy per } \\
\text { Stone, } \mathrm{n}\end{array}$ & $\begin{array}{l}\text { Strikes per } \\
\text { Stone, } \mathrm{n}\end{array}$ & $\begin{array}{l}\text { Time of Lithotripsy } \\
\text { or Stone, min }\end{array}$ & \\
\hline \multirow[t]{2}{*}{ All stones $(39 ; 50)$} & $6.68 \pm 0.46$ & $1.18 \pm 0.09$ & $120.28 \pm 21.97$ & $67.4 \pm 8.6$ & $49(98)^{a}$ \\
\hline & $(6.15 ; 2.4-15)$ & $(1.0 ; 0.2-4)$ & $(64.5 ; 6-734)$ & $(47 ;$ II-337) & \\
\hline \multirow[t]{2}{*}{ Persistent stones $(4 ; 4)$} & $10.92 \pm 1.52$ & $1.5 \pm 0.29$ & $295.75 \pm 58.49$ & $124.5 \pm 31.37$ & $4(100)$ \\
\hline & $(10.5 ; 7.7-15)$ & $(1.5 ; 1-2)$ & $(324.5 ; 132-402)$ & $(131 ; 43-193)$ & \\
\hline \multirow[t]{2}{*}{ Residual stones $(16 ; 24)$} & 5.74. \pm 061 & $1.16 \pm 0.16$ & $113.83 \pm 31.73$ & $71.58 \pm 14.05$ & $24(100)$ \\
\hline & $(5.25 ; 2.4-15)$ & $(1.0 ; 0.2-4)$ & $(52 ; 6-734)$ & $(45 ; 11-337)$ & \\
\hline \multirow[t]{2}{*}{ Recurrent stones $(19 ; 22)$} & $6.94 \pm 0.67$ & $1.14 \pm 0.10$ & $95.41 \pm 31.15$ & $52.36 \pm 9.48$ & $21(95.5)^{\mathrm{a}}$ \\
\hline & $(6.55 ; 3-13.5)$ & $(1.0 ; 1-3)$ & $(59 ; 8-7 \mid 4)$ & $(47 ; 14-234)$ & \\
\hline$P$ value & .019 & ns & .027 & ns & ns \\
\hline
\end{tabular}

Abbreviations: eTDS, extended transoral duct surgery; IPL, intraductal pneumatic lithotripsy; ns, not significant; SMG, submandibular gland.

${ }^{a}$ One stone was removed subtotal/nearly complete; after mobilization, conventional removal was possible without need for further IPL.

stones (18 of 35). Multiple stones were treated with IPL in 9 patients (Table I).

Four patients had persistent stones after eTDS without successful stone retrieval due to far posthilar to intraparenchymal locations (1 stone each). IPL was used as a salvage procedure for these patients. For 1 patient, prior eTDS had been performed in another hospital. TDS had been unsuccessful in 1 patient due to a strong gag reflex. In 2 cases, it was not possible to access and extract the stone despite adequate preoperative criteria. These patients had large stones (average size, nearly $10 \mathrm{~mm}$ ) that were located nearly intraparenchymally, and they were informed before the start of the therapy that additional treatment (IPL and/or ESWL) might be necessary to reach a stone-free state. Additional ESWL was performed for 2 patients after unsuccessful TDS to improve accessibility. For 1 patient, additional hilar stenosis was dilated and a stent implanted. All 4 patients became stone-free (Table 2).

Sixteen patients with residual stones had primary multiple sialolithiasis, with the number of stones ranging from 2 to 11 (sample case report: Figures I-4). Extraction of 1 to 8 stones was previously performed by eTDS. Of the 49 stones, 24 were treated with IPL as a primary procedure (Table I). In 3 cases, the stones became adequately or better accessible after additional ESWL; in another case, a residual fragment was treated successfully with ESWL after IPL. In 1 of these cases, a posthilar stenosis had to be dilated before IPL could be performed. One patient had 11 stones: 6 were removed with eTDS and 2 with IPL; 3 intraparenchymal stones (not accessible with the sialendoscope) were treated with ESWL; and finally a spontaneous washout occurred. Of 16 patients with residual stones after eTDS, 15 (93.7\%) became stone-free. One patient developed recurrent sialolithiasis 9 months after IPL and was treated successfully with ISE (Tables I and 2).

Nineteen patients presented with recurrent stones after successful stone extraction with eTDS, which had been performed on average 68.94 months before (mean, 49; range,
26-147). Two cases had eTDS in another department. IPL was considered a salvage procedure in these cases, and 1 to 3 stones were treated (Table I). In 1 case, a narrow

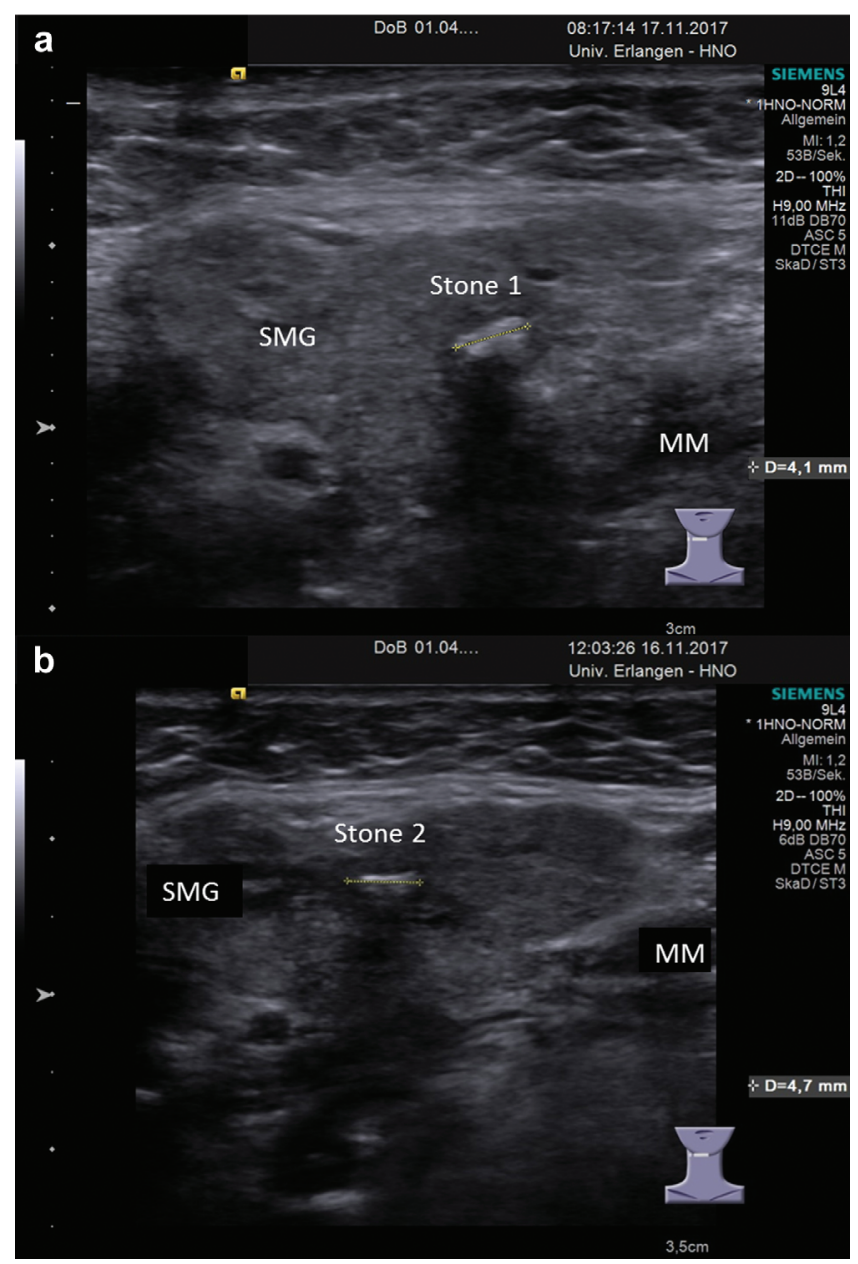

Figure I. Ultrasound at 2 months after removal of a hilar stone by extended transoral duct surgery. Hyperechoic reflexes indicate 2 residual stones: (a) I posthilar (4.I mm) and (b) I intraparenchymal (4.7 mm). MM, mylohyoid muscle; SMG, submandibular gland. 


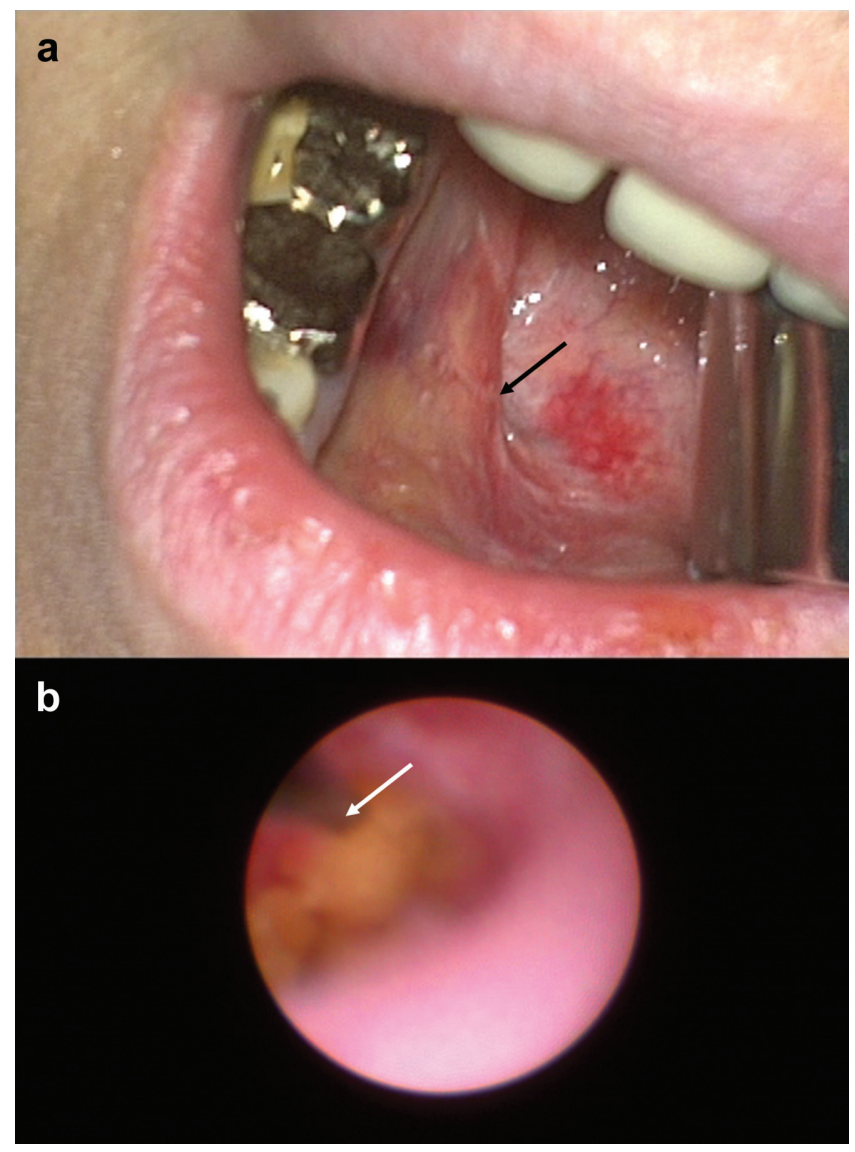

Figure 2. (a) Posterior neo-ostium in the floor of the mouth 8 weeks after extended transoral duct surgery (black arrow). (b) Intraductal lithotripsy through the neo-ostium showing the probe (white arrow) positioned on the stone surface.

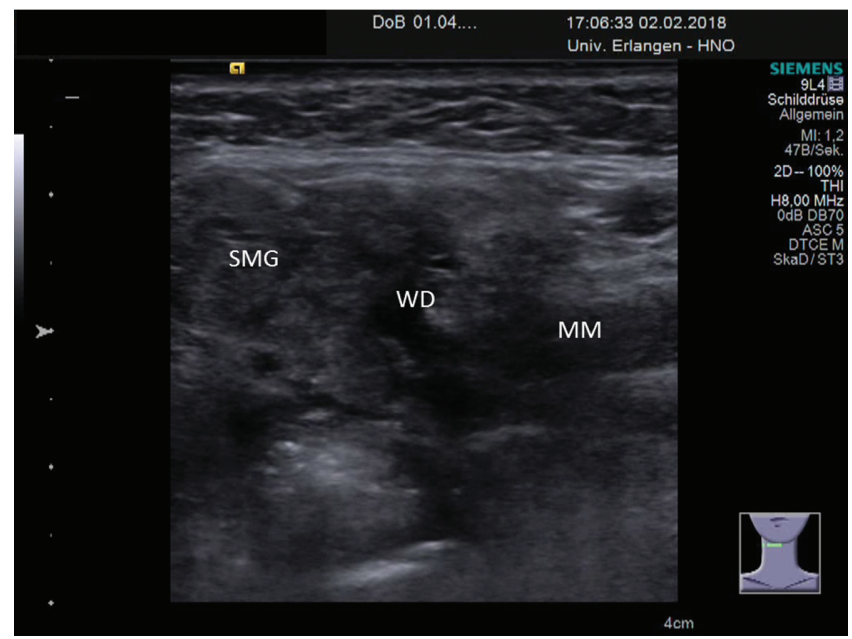

Figure 3. Ultrasound after intraductal lithotripsy for 2 residual stones. No hyperechoic reflexes are recognizable in the hilar and intraparenchymal area. DW, Wharton's duct; MM, mylohyoid muscle; SMG, submandibular gland.

neo-ostium was widened with revision eTDS, and 1 additional stone was extracted before IPL could be performed for the second. In another case, subtotal/nearly complete fragmentation of a large stone with IPL had been achieved, and the mobilized fragments could be removed conventionally through the neo-ostium the next day. In a further case, the stone was adequately accessible only after additional ESWL. In 1 patient, ESWL and IPL were carried out due to multiple stones. Altogether, 22 of 25 stones that occurred after prior eTDS were treated with IPL. All 19 patients treated became stone-free. In 3 of these, further recurrences were noted. One patient developed another recurrence after 15 months, which was treated successfully by ISE. Multiple recurrences were noted in 2 cases, starting 3 to 4 months after IPL was performed. All could be treated successfully by ISE and/or another IPL (Tables I and 2). Due to the numerous recurrences (4 and 5) within short time intervals (weeks to months), gland extirpation was recommended and eventually conducted without complications after 22 and 24 months, respectively.

Comparisons among patients with persistent, residual, and recurrent stones with regard to stone size, number of strikes per stone, number of IPLs per stone, and duration of IPL per stone showed significant differences. Persistent stones were significantly larger and needed significantly more strikes per stone in comparison with the other 2 groups (persistent vs recurrent stones, $P=.026$ and $P=.004$; persistent vs residual stones, $P=.007$ and $P=.012$, respectively). The duration of IPL per stone was considerably longer in persistent stones in comparison with residual stones $(P=.070)$, and the difference was significant in comparison with recurrent stones $(P=.048)$. No differences were noted when residual and recurrent stones were compared.

Check-up endoscopies on the first 2 days and 4 to 8 weeks after IPL were performed for all patients. The follow-up period was at least 1 year for $50 \%$ of the patients who have so far received a check-up sialendoscopy. No cases of severe complications, scar formation, or stenosis in the ductal system have been observed.

Four patients $(10.2 \%)$ have had recurrences so far, with several-stone recurrences in 2 of them, which resulted in submandibulectomy (see Table I).

\section{Discussion}

This study investigated the value of pneumatic IPL in the treatment of 39 patients with persistent $(10.2 \%)$, residual (41\%), and recurrent stones (48.2\%) after eTDS. All patients presented with a neo-ostium located dorsally near transition of the glossoalveolar sulcus to the basal region of the anterior palatal arch. The stones were all in posthilar or even (nearly) intraparenchymal locations; $98 \%$ of the stones were completely fragmented and 1 nearly complete; and $97.4 \%$ of the patients became stone-free and all symptomfree. All glands were preserved after this treatment cycle (Tables I and 2). These data show that good results can be obtained in difficult cases of submandibular sialolithiasis after eTDS.

In a multimodal treatment regimen, ${ }^{3-8,39}$ ISE and TDS/ eTDS proved to be the most important in submandibular sialolithiasis. Fifty percent of stones are found in hilar to 


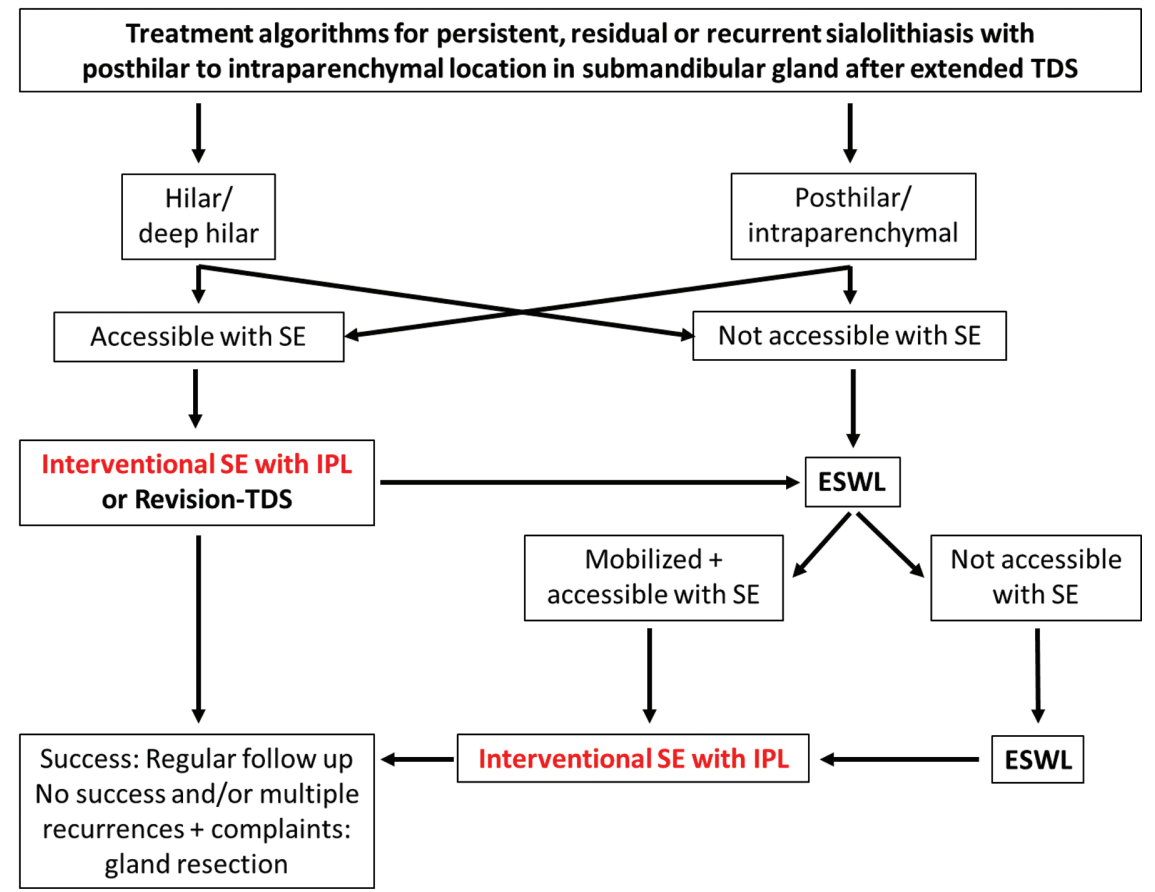

Figure 4. Treatment algorithms for persistent, residual, or recurrent sialolithiasis after extended transoral duct surgery. ESWL, extracorporeal shock wave lithotripsy; IPL, intraductal pneumatic lithotripsy; SE, sialendoscopy; TDS, transoral duct surgery.

intraparenchymal locations. ${ }^{1,2}$ In this area, eTDS with or without submandibulectomy, assistance with sialendoscopy, and ultrasound guidance is the most important treatment approach, with successful results in $70 \%$ to $100 \%$ of reported cases among adults and children. ${ }^{9-25}$

The limitations of ISE and TDS/eTDS are associated with the anatomy of the gland itself and the ductal system, particularly the angle of the comma area. ${ }^{19,29,31}$ In addition, the anatomy of the floor of the mouth (breadth, depth), the course of the lingual nerve, a small and/or reduced opening of the mouth, a strong gag reflex, a small stone size, and an unfavorable location may prevent successful stone removal with eTDS despite careful preoperative evaluation. ${ }^{37}$

Persistent and/or residual deep hilar to intraparenchymal stones may therefore be left in situ in up to $30 \%$ of cases. In 1 study, we investigated the results after eTDS in proximal stones exclusively in deep hilar to even intraparenchymal locations, including cases of multiple sialolithiasis, among $>230$ patients and reported a primary success rate of $76 \%$. This increased to $82.3 \%$ after additional measures (eg, ISE or ESWL). ${ }^{19}$ This publication included patients who were treated before IPL was incorporated into our treatment regimen. After introduction of IPL, we could treat all stones with comparable locations successfully. ${ }^{37}$

Among the cases reported in this article, all 4 patients with persistent sialolithiasis were treated successfully with IPL (Tables I and 2). All stones were large, strongly impacted, and in deep locations. The current treatment strategy may be changed for stones with deep locations (eg, $>6.5-7 \mathrm{~cm}$ within the ductal system). If a stone is obviously located too deep, primary IPL may be performed, or eTDS can be carried out in preparation for later IPL. ESWL would not be the most promising solution in such cases, since relatively large fragments have to be washed out through a more or less narrow and bending ductal system or neo-ostium.

Residual stones are often located nearly or entirely intraparenchymal, and all of these patients have multiple stones, ${ }^{31}$ as evident in the patients included in the present study. One must be prepared to treat these patients. As reported in the literature, $10 \%$ of all stones are primarily located intraparenchymally, and about $18 \%$ of patients present with multiple sialolithiasis. ${ }^{1,2}$ In the present study, for $35.7 \%$ of patients with residual stones, several stones were treated with IPL. "Genuinely" intraparenchymal stones that are not accessible with sialendoscopy could be treated with ESWL, ${ }^{5-7,35}$ and this was the only possible treatment modality for some of the stones in 1 of these patients. ESWL has lower success rates in the submandibular gland. ESWL alone may not be sufficiently effective to produce fragments small enough to be washed out spontaneously through a narrow and bended ductal system or neo-ostium. ${ }^{29,30,34,35}$ However, stones treated with ESWL can often be mobilized into the posthilar duct system and then accessible with the sialendoscope. As such, IPL offers an excellent opportunity for further therapy, ${ }^{40}$ as confirmed by our data. All patients with residual stones and multiple sialolithiasis became symptom-free, and $93.7 \%$ became stone-free (Tables I and 2).

Around $5 \%$ to $15 \%$ of patients develop recurrent stones after TDS/eTDS. ${ }^{2,25,32,33}$ By definition, these stones are in at least posthilar or even intraparenchymal locations and present the same difficulties and limitations as discussed here. All patients in this study who presented with recurrent stones became stone-free and symptom-free after IPL (Tables I and 2), confirming the value of IPL for this situation. 
To explain the positive effect that IPL has on our patients when performed after eTDS, we emphasize that after eTDS, IPL can be more effectively performed through an existing dorsal neo-ostium because the anatomic preconditions have changed. As the ductal system has been opened, the angle of the comma area is no longer an obstacle, as compared with the situation where no eTDS had been performed. The sialendoscope can now be inserted at a more favorable angle, and deeper ductal structures can be accessed. Stones in unfavorable locations may now become accessible, and IPL can be effectively applied in the posthilar duct system. Intraductal lithotripsy, pneumatic or laser, was recently reported with success rates $>90 \%$ for patients with sialolithiasis. ${ }^{36-38}$ This effectiveness was confirmed in the present study. The success rates presented here underscore that IPL offers an excellent way to treat patients with complicated sialolithiasis after prior eTDS, as well as the potential to change the established treatment algorithms. ${ }^{6,8}$ Treatment algorithms considering the advances that proved to be effective in these situations are outlined in Figure 4.

As the sialendoscope cannot be inserted into the ductal system any more immediately after eTDS, IPL can be performed after an interval of at least 6 to 8 weeks in persistent or residual sialolithiasis. After the healing period, the neoostium is often relatively narrow due to scar tissue, and a ductal channel of up to $1 \mathrm{~cm}$ can often be observed before the stone bed is reached. In some but not all situations, revision eTDS may be an alternative. But this technique holds a risk of damage to the ductal system and serious scarring, which can be avoided with sialendoscopy-guided IPL.

In general, patients with such complicated sialolithiasis have to be prepared for several therapeutic procedures and should receive adequate counseling before the start of treatment, especially in cases of multiple sialolithiasis (Figure 4). In addition, multiple recurrences after short intervals indicate that achieving a durable symptom-free state may not be possible and that gland resection is necessary.

One patient $(2.6 \%)$ in this study did not become stonefree after presenting with residual/multiple stones. He had residual fragments (up to 3-4 $\mathrm{mm}$ ) in a posthilar location, and successful therapy with complete stone clearance appears to be possible.

Multiple recurrences after successful therapy occurred within short intervals for 2 patients (Table I), and all of the recurrences were treated successfully. However, gland resection was recommended for and performed in both patients, suggesting that a situation of this type shows the limitations of gland-preserving therapy. ${ }^{41}$ In this setting, new limitations in the treatment of submandibular sialolithiasis include multiple intraparenchymal stones (for which primary extracorporeal shock wave lithotripsy or gland resection is indicated) and/or multiple recurrences within short intervals (in which gland resection may be recommended).

\section{Conclusions}

eTDS may result in persistent, residual, and/or recurrent stones. Further advances in ISE and the introduction of intraductal pneumatic lithotripsy in particular, which can be administered with high success rates $(>97 \%)$, are clearly additional treatment options and may have the potential to change established treatment algorithms, especially for patients with deep hilar, posthilar, and (nearly) intraparenchymal stone locations, as well as multiple and/or recurrent sialolithiasis.

\section{Author Contributions}

Michael Koch, substantial contributions to the conception and design of the work; the acquisition, analysis, interpretation of data for the work, drafting the work and revising it critically for important intellectual content, final approval of the version to be published, agreement to be accountable for all aspects of the work in ensuring that questions related to the accuracy or integrity of any part of the work are appropriately investigated and resolved; Mirco Schapher, data interpretation, drafting revising the work critically for important intellectual content, final approval of the version to be published, accountability for the work; Konstantinos Mantsopoulos, data interpretation, revising the work critically for important intellectual content, final approval of the version to be published, accountability for the work; Miguel Goncalves, data analysis, revising the work critically for important intellectual content, final approval of the version to be published, accountability for the work; Heinrich Iro, data interpretation, revising the work critically for important intellectual content, final approval of the version to be published, accountability for the work.

\section{Disclosures}

Competing interests: None.

Sponsorships: None.

Funding source: None.

\section{References}

1. Sigismund PE, Zenk J, Koch M, Schapher M, Rudes M, Iro H. Nearly 3,000 salivary stones: some clinical and epidemiologic aspects. Laryngoscope. 2015;125:1879-1882.

2. Lustmann J, Regev E, Melamed Y. Sialolithiasis: a survey on 245 patients and a review of the literature. Int $J$ Oral Maxillofac Surg. 1990;19:135-138.

3. McGurk M, Escudier MP, Brown JE. Modern management of salivary calculi. Br J Surg. 2005;92:107-112.

4. Capaccio P, Torretta S, Ottavian F, Sambataro G, Pignataro L. Modern management of obstructive salivary diseases. Acta Otorhinolaryngol Ital. 2007;27:161-172.

5. Iro H, Zenk J, Escudier MP, et al. Outcome of minimally invasive management of salivary calculi in 4,691 patients. Laryngoscope. 2009;119:263-268.

6. Koch M, Zenk J, Iro H. Algorithms for treatment of salivary gland obstructions. Otolaryngol Clin North Am. 2009;42: 1173-1192.

7. Zenk J, Koch M, Klintworth N, et al. Sialendoscopy in the diagnosis and treatment of sialolithiasis: a study on more than 1000 patients. Otolaryngol Head Neck Surg. 2012;147:858-863.

8. Foletti JM, Graillon N, Avignon S, Guyot L, Chossegros C. Salivary calculi removal by minimally invasive techniques: a decision tree based on the diameter of the calculi and their position in the excretory duct. J Oral Maxillofac Surg. 2018; 119:2-7. 
9. Zenk J, Constantinidis J, Al-Kadah B, Iro H. Transoral removal of submandibular stones. Arch Otolaryngol Head Neck Surg. 2001;127:432-436.

10. McGurk M, Makdissi J, Brown JE. Intra-oral removal of stones from the hilum of the submandibular gland: report of technique and morbidity. Int J Oral Maxillofac Surg. 2004;33:683-686.

11. Capaccio P, Bottero A, Pompilio M, Ottaviani F. Conservative transoral removal of hilar submandibular salivary calculi. Laryngoscope. 2005;115:750-752.

12. Kim JK, Park JS. Ultrasound-guided transoral removal of impalpable hilar submandibular salivary stones. Laryngoscope. 2007; 117:1373-1375.

13. Roh JL, Park CI. Transoral removal of submandibular hilar stone and sialodochoplasty. Otolaryngol Head Neck Surg. 2008;139:235-239.

14. Combes J, Karavidas K, McGurk M. Intraoral removal of proximal submandibular stones - an alternative to sialadenectomy? Int J Oral Maxillofac Surg. 2009;38:813-816.

15. Woo SH, Jang JY, Park GY, Jeong HS. Long-term outcomes of intraoral submandibular stone removal in children as compared with adults. Laryngoscope. 2009;119:116-120.

16. Zhang L, Escudier M, Brown J, Capaccio P, Pignataro L, McGurk M. Long-term outcome after intraoral removal of large submandibular gland calculi. Laryngoscope. 2010;120: 964-966.

17. Eun YG, Chung DH, Kwon KH. Advantages of intraoral removal over submandibular gland resection for proximal submandibular stones: a prospective randomized study. Laryngoscope. 2010;120:2189-2192.

18. Capaccio P, Clemente IA, McGurk M, Bossi A, Pignataro L. Transoral removal of hiloparenchymal submandibular calculi: a long-term clinical experience. Eur Arch Otorhinolaryngol. 2011;268:1081-1086.

19. Schapher M, Mantsopoulos K, Messbacher ME, Iro H, Koch M. Transoral submandibulotomy for deep hilar submandibular gland sialolithiasis. Laryngoscope. 2017;127:2038-2044.

20. Marchal F. A combined endoscopic and external approach for extraction of large stones with preservation of parotid and submandibular glands. Laryngoscope. 2007;117:373-377.

21. Liu DG, Jiang L, Xie XY, Zhang ZY, Zhang L, Yu GY. Sialoendoscopy-assisted sialolithectomy for submandibular hilar calculi. J Oral Maxillofac Surg. 2013;71:295-301.

22. Klein H, Ardekian L. The treatment of large sialoliths by sialendoscopic combined approach. J Oral Maxillofac Surg. 2014;72:737-743.

23. Schwartz N, Hazkani I, Goshen S. Combined approach sialendoscopy for management of submandibular gland sialolithiasis. Am J Otolaryngol. 2015;36:632-635.

24. Xiao JQ, Sun HJ, Qiao QH, Bao X, Wu CB, Zhou Q. Evaluation of sialendoscopy-assisted treatment of submandibular gland stones. J Oral Maxillofac Surgery. 2017;75:309-316.

25. Capaccio P, Gaffuri M, Rossi V, Pignataro L. Sialendoscopeassisted transoral removal of hilo-parenchymal sub-mandibular stones: surgical results and subjective scores. Acta Otorhinolaryngol Ital. 2017;37:122-127.

26. Woo SH, Kim JP, Kim JS, Jeong HS. Anatomical recovery of the duct of the submandibular gland after transoral removal of a hilar stone without sialodochoplasty: evaluation of a phase II clinical trial. Br J Oral Maxillofac Surg. 2014;52:951-956.

27. Seward GR.Anatomic surgery for salivary calculi: V. Calculi in the extraglandular part of the parotid duct. Oral Surg Oral Med Oral Pathol. 1968;25:810-816.

28. Seward GR.Anatomic surgery for salivary calculi: IV. Calculi in the intraglandular part of the submandibular duct. Oral Surg Oral Med Oral Pathol. 1968;25:670-678.

29. Drage NA, Wilson RF, McGurk M. The genu of the submandibular duct - is the angle significant in salivary gland disease? Dentomaxillofac Radiol. 2002;31:15-18.

30. Zenk J, Bozzato A, Winter M, Gottwald F, Iro $\mathrm{H}$. Extracorporeal shock wave lithotripsy of submandibular stones: evaluation after 10 years. Ann Otol Rhinol Laryngol. 2004; 113:378-383.

31. Gerni M, Foletti JM, Collet C, Chossegros C. Evaluation of the prevalence of residual sialolith fragments after transoral approach of Wharton's duct. J Craniomaxillofac Surg. 2017; 45:167-170.

32. Park JH, Kim JW, Lee YM, Oh CW, Chang HS, Lee SW. Long-term study of sialodochoplasty for preventing submandibular sialolithiasis recurrence. Clin Exp Otorhinolaryngol. 2012;5:34-38.

33. Kim JK, Shin SM, Lee H, Lee S. Factors affecting long-term outcome of transoral surgery for submandibular stones: a follow-up study of 125 patients. Clin Otolaryngol. 2016;41: 365-370.

34. Escudier MP, Brown JE, Putcha V, Capaccio P, McGurk M. Factors influencing the outcome of extracorporeal shock wave lithotripsy in the management of salivary calculi. Laryngoscope. 2010;120:1545-1549.

35. Capaccio P, Torretta S, Pignataro L, Koch M. Salivary lithotripsy in the era of sialendoscopy. Acta Otorhinolaryngol Ital. 2017;37:113-121.

36. Martellucci S, Pagliuca G, de Vincentiis M, et al. Ho:Yag laser for sialolithiasis of Wharton's duct. Otolaryngol Head Neck Surg. 2013;148:770-774.

37. Koch M, Mantsopoulos K, Schapher M, von Scotti F, Iro H. Intraductal pneumatic lithotripsy for salivary stones with the StoneBreaker: preliminary experience. Laryngoscope. 2016; 126:1545-1550.

38. Serbetci E, Celikoyar MM, Altundag A. Sialendoscopic pneumatic lithotripsy for salivary calculi: a new technique and a long-term clinical experience. Otolaryngol Head Neck Surg. 2017;157:906-908.

39. Marchal F, Dulguerov P. Sialolithiasis management: the state of the art. Arch Otolaryngol Head Neck Surg. 2003;129:951-956.

40. Koch M, Schapher M, Mantsopoulos K, von Scotti F, Goncalves M, Iro H. Multimodal treatment in difficult sialolithiasis: role of extracorporeal shock-wave lithotripsy and intraductal pneumatic lithotripsy [published online December 15, 2017]. Laryngoscope. doi:10.1002/lary.27037

41. Trujillo O, Drusin MA, Rahmati R. Rapid recurrent sialolithiasis: altered stone composition and potential factors for recurrence. Laryngoscope. 2017;127:1365-1368. 